\title{
Neutrophil transepithelial migration: role of toll-like receptors in mucosal inflammation
}

\author{
Titus A Reaves, Alex C Chin, Charles A Parkos ${ }^{+}$
}

\author{
Epithelial Pathobiology Research Unit, Department of Pathology and Laboratory Medicine, Emory University, \\ 615 Michaels Street, Atlanta, GA 30322, US
}

\begin{abstract}
The symptomatic phases of many inflammatory diseases are characterized by migration of large numbers of neutrophils (PMN) across a polarized epithelium and accumulation within a lumen. For example, acute PMN influx is common in diseases of the gastrointestinal system (ulcerative colitis, Crohn's disease, bacterial enterocolitis, gastritis), hepatobiliary system (cholangitis, acute cholecystitis), respiratory tract (bronchial pneumonia, bronchitis, cystic fibrosis, bronchiectasis), and urinary tract (pyelonephritis, cystitis). Despite these observations, the molecular basis of leukocyte interactions with epithelial cells is incompletely understood. In vitro models of PMN transepithelial migration typically use $\mathrm{N}$-formylated bacterial peptides such as fMLP in isolation to drive human PMNs across epithelial monolayers. However, other microbial products such as lipopolysaccharide (LPS) are major constituents of the intestinal lumen and have potent effects on the immune system. In the absence of LPS, we have shown that transepithelial migration requires sequential adhesive interactions between the PMN $\beta 2$ integrin $C D 11 b / C D 18$ and JAM protein family members. Other epithelial ligands appear to be abundantly represented as fucosylated proteoglycans. Further studies indicate that the rate of PMN migration across mucosal surfaces can be regulated by the ubiquitously expressed transmembrane protein CD47 and microbial-derived factors, although many of the details remain unclear. Current data suggests that Toll-like receptors (TLR), which recognize specific pathogen-associated molecular patterns (PAMPs), are differentially expressed on both leukocytes and mucosal epithelial cells while serving to modulate leukocyte-epithelial interactions. Exposure of epithelial TLRs to microbial ligands has been shown to result in transcriptional upregulation of inflammatory mediators whereas ligation of leukocyte TLRs modulate specific antimicrobial responses. A better understanding of these events will hopefully provide new insights into the mechanisms of epithelial responses to microorganisms and ideas for therapies aimed at inhibiting the deleterious consequences of mucosal inflammation.
\end{abstract}

Key words: neutrophil migration - ephitelium - Toll-like receptor - cell surface proteins - mucosal inflammation

Neutrophil (PMN) transepithelial migration plays a major role in mucosal-epithelial defense in inflammatory diseases. When the inflammatory response is initiated at the epithelium, PMNs must exit the bloodstream traverse the endothelium, the lamina propria, and then the tight junction to finally reach the lumenal side of epithelium. Unlike other epithelial surfaces in the body, the intestinal epithelium is exposed to high levels of microbes and microbial products (Fenton \& Golenbock 1998, Hecht 1999, Cario et al. 2000). Consequently, the intestinal epithelium plays a pivotal role in regulating the inflammatory response to pathogens and commensal microflora. Thus, what seems to be a passive coexistence of the host and beneficial microbial flora might reflect a constant battle between stop and go signals to the epithelial innate immune system. Despite this delicate balance, there is apparent dysregulation of mucosal homeostasis resulting in massive migration of PMNs toward the lumenal epithelial surface followed by accumulation of these PMNs within the lumen during many inflammatory disease states of the gastrointestinal tract (Parkos 1997). Details of the mechanisms governing the regulation of migration of leukocytes across intestinal mucosa are just beginning to be under-

+Corresponding author. E-mail: cparkos@emory.edu Received 8 November 2004

Accepted 30 December 2004 stood (Sabroe et al. 2003). This review will focus on the mechanisms of leukocyte interactions with epithelia and discuss the role of the TLRs and microbial products in mucosal inflammation.

Leukocyte-epithelial interactions and disease pathophysiology

It is well accepted that in many inflammatory disorders of the gastrointestinal tract, the combination of epithelial injury, disease activity and symptoms parallel PMN infiltration of the mucosa (Hawker et al. 1980, Weiland et al. 1986, Koyama et al. 1991, Nusrat et al. 1997). The etiology of disease symptoms associated with PMN transepithelial migration is complex but a major component is related to the effects of PMNs on the epithelial barrier and on epithelial cell function. For example, while studies have shown that passage of a single PMN across epithelial tight junctions results in rapid resealing with little loss of barrier function (Milks et al. 1983, Nash et al. 1987, Parsons et al. 1987), large scale PMN migration results in the formation of sizable epithelial discontinuities (Nusrat et al. 1997) that likely represent the precursors of epithelial erosions and ulcers characteristic of many of the inflammatory conditions mentioned above. Direct effects of PMNs on epithelial cell function appear to be mediated both by cell-cell contact and by release of factors that initiate subsequent signaling events. For example, we have recently shown that as sub-epithelial 
PMNs enter the paracellular space in response to a lumenal chemoattractant, epithelial permeability increases through undefined mechanisms that are independent of junctional disruption (Edens et al. 2002). In addition, as PMNs migrate across the colonic epithelium, PMN-derived 5'-AMP (Madara et al. 1993) is converted to adenosine which activates electrogenic chloride secretion and passive water movement into the lumen (Strohmeier et al. 1995, 1997). This represents the molecular basis of secretory diarrhea, a major symptom in patients with inflammatory bowel disease. Such findings serve to shed light on how signals derived from migrating PMN might be efficiently amplified to produce functional responses in the epithelium.

\section{The molecular basis of PMN transepithelial migration}

Before discussing the contribution of microbes in modulating innate immune cell interactions with epithelial cells, it is worth reviewing what is currently known about how acute inflammatory cells, PMNs in particular, interact with and migrate across mucosal epithelia. PMN transepithelial migration can be viewed as a multi-step response that can be initiated by both host and pathogen derived stimuli such as IL-8 and $N$-formylated peptides respectively (Prossnitz \& Ye 1997, Tavares-Murta et al. 2002, Ramos et al. 2003) From our studies and those of others (Parkos et al. 1991, Tosi et al. 1992, Agace et al. $1995)$, it is clear that the $\beta 2$ integrin CD11b/CD18 is central in regulating early adhesive events in the transepithelial migration response. PMN adhesion to epithelial monolayers can be blocked using monoclonal antibodies to $\mathrm{CD} 11 \mathrm{~b}$, and furthermore, using specific antibodies in mapping studies, it was demonstrated that a domain consisting of 200 amino acids (I domain) is a major binding region for CD11b/CD18 ligands, including those on intestinal epithelial cells (Parkos et al. 1991, Balsam et al. 1998). While investigators have actively sought to identify epithelial ligands for $\mathrm{CD} 11 \mathrm{~b} / \mathrm{CD} 18$ over the past decade, only recently have clues emerged uncovering the nature of these cellular ligands. There is evidence that CD11b/CD18 may bind to oligosaccharide determinants on epithelial cells (Colgan et al. 1995, Diamond et al. 1995, Zen et al. 2002) For example, sulfated polysaccharides such as heparin and heparan sulfate proteoglycans have been shown to bind CD11b/CD18 (Diamond et al. 1995). In addition, published reports show that fucosylated proteoglycans also bind to CD11b/CD18 and inhibit epithelial cell adhesion in vitro (Zen et al. 2002). Lastly, as detailed below, there is now compelling evidence for involvement of epithelial JAM protein family members as adhesive receptors for CD11b/CD18 on migrating PMN.

Efforts aimed at characterizing proteins important in the regulation of PMN transepithelial migration identified a membrane protein termed CD47 (Parkos et al. 1996). CD47 is a multiple membrane spanning immunoglobulin superfamily member (Lindberg et al. 1993) with several cytoplasmic tail splice variants that we have shown to play a significant role in facilitating PMN migration after initial $\beta 2$ integrin dependent adhesion (Parkos et al. 1996). This is perhaps best illustrated by the observation that antiCD47 mAbs potently inhibit the initiation of transmigra- tion but have no effect on adhesion (Parkos et al. 1996). Interestingly, CD47 is universally expressed in all cells including epithelia, and has many other functions (reviewed in Brown 2001) that are the focus of intense investigation and beyond the scope of this review. Our studies suggest that CD47 expressed by both PMNs and epithelia facilitates PMN transmigration (Parkos et al. 1996, Liu et al. 2001) This is supported by in vivo studies with CD47 knockout mice (Lindberg et al. 1996) in which CD47 deficient animals rapidly succumb to Escherichia coli sepsis due to delayed recruitment of PMNs to the site of infection.

The recent identification of a cellular receptor for $\mathrm{CD} 47$ as signal regulatory protein alpha (SIRP $\alpha$ ) (Jiang et al. 1999), provided new insights into the mechanism of CD47 function in regulating PMN migration through tissues. SIRP $\alpha$ is one of over a dozen SIRP members belonging to the transmembrane immunoglobulin superfamily, and it possesses a C-terminal intracellular domain containing four tyrosine residues that form two immunoreceptor tyrosine-based inhibitory motifs (ITIMs). Similar to other ITIM domain containing proteins, SIRP $\alpha$ has been implicated in both positive and negative regulation of cellular responses to a wide variety of different stimuli through ligand induced interactions with tyrosine phosphatase-1 or 2 (SHP-1 and 2) (Stofega et al. 2000). We have observed that no SIRP $\alpha$-CD47 binding interactions can result in inhibited or enhanced PMN transmigration due to bi-directional signaling pathways with different functional consequences depending on how the ligand is presented. Indeed, enhanced intestinal epithelial expression of CD47 such as that observed in inflammatory bowel disease results in enhanced PMN transepithelial migration whereas soluble CD47 inhibits PMN transmigration (Liu et al. 2001, 2002, Zen \& Parkos 2003).

Recently, members of a growing family of transmembrane immunoglobulin superfamily members termed junctional adhesion molecules or JAMs have been shown to play roles as adhesion receptors during leukocyte transmigration. Interestingly, multiple members of the JAM protein family have also been shown to act as receptors for viruses (Bergelson et al. 1997, Barton et al. 2001) and have been shown to localize to intercellular junctions (Martin-Padura et al. 1998, Liu et al. 2000, Cohen et al. 2001). The JAM proteins are type I transmembrane proteins consisting of an $N$-terminal signal peptide, an extracellular domain, a single membrane-spanning domain and a short cytoplasmic tail (Malergue et al. 1998, MartinPadura et al. 1998, Ozaki et al. 1999, Williams et al. 1999, Cunningham et al. 2000, Liu et al. 2000, Palmeri et al. 2000, Sobocka et al. 2000, Arrate et al. 2001, Aurrand-Lions et al. 2001a,b, Naik et al. 2001, Liang et al. 2002, Santoso et al. 2002, Hirabayashi et al. 2003, Moog-Lutz et al. 2003). The extracellular domains of JAMs consist of two immunoglobulin-like loops, each containing an intradomain disulfide bond while the cytoplasmic tails of several members terminate in putative PDZ-binding motifs that appear to mediate binding to intercellular junction-associated scaffold proteins (Cunningham et al. 2000, Ebnet et al. 2000, 2001, Martinez-Estrada et al. 2001, Hamazaki et al. 2002, Santoso et al. 2002, Hirabayashi et al. 2003). 
A variety of functional studies have implicated a role for JAMs in leukocyte transendothelial migration, however until recently, none had been shown to play a role in transepithelial migration of leukocytes. In particular, studies from our group recently demonstrated that JAM-C regulates transepithelial migration of PMNs at the level of epithelial desmosomes (Zen et al. 2004) In contrast to other JAM protein family members, JAM-C is not expressed at the tight junction (TJ), but is abundantly expressed at epithelial desmosomes. Indeed, disruption of desmosomes, but not TJs, results in redistribution of JAMC. Significantly, antibodies against JAM-C and JAM-C fusion proteins, both inhibit PMN transepithelial migration. Furthermore, our studies have shown that JAM-C binds specifically to CD11b/CD18. Interestingly, PMN interactions with epithelial JAM-C occur at points distal to initial adhesive interactions with the epithelial basolateral membrane, thus lending further support for the existence of multiple epithelial ligands for migrating PMNs. In closing this section, it is important to note that other adhesion molecules such as ICAM-1 for example, have been reported to bind CD11b/CD18 (Diamond et al. 1990) However, ICAM-1 is only expressed on apical epithelial surfaces under inflammatory conditions, which makes ICAM-1 inaccessible to PMNs until after reaching the lumenal surface (Parkos 1997).

Microbial-derived products and the inflammatory response

Currently, many studies are focusing on the events signaling the initiation of PMN transepithelial migration with a particular interest in the role of microbes in inducing mucosal inflammation. Microbes have been shown to elicit epithelial secretion of PMN chemoattractants such as IL-8. Furthermore, microbes themselves can directly release $N$-formylated bacterial peptides which are potent PMN chemoattractants and are typically used in most studies focusing on PMN transepithelial migration. Before reviewing the specific contributions of microbial-derived products to mucosal inflammation, it is worth briefly discussing the Toll-like receptors (TLRs).

It is now widely accepted that TLRs play a major role in the recognition of pathogen-associated molecular patterns (PAMPs) present on bacteria and bacterial products while also serving to limit the damage that pathogenic bacteria cause to mammalian systems (Kopp \& Medzhitov 2003, Sabroe et al. 2003). TLRs were originally identified as a developmental component in wing patterning of Drosophila and have emerged as signaling receptors vital for immune responses to bacteria and their products (Medzhitov \& Janeway 1997, Medzhitov et al. 1997). At present, eleven different TLRs have been discovered, and are described as type 1 transmembrane receptors that contain an N-terminal extracellular leucine-rich repeat domain and a C-terminal tail containing a Toll/IL-1 receptor homology domain (Takeda et al. 2003, Zhang et al. 2004). TLRs are expressed by most immune cells including PMN as well as epithelial cells. While recent studies have uncovered a number of different TLRs, a majority of the research has focused on TLR4 which was the first of these receptors to be discovered, and to a lesser extent TLR2 (Cario et al. 2000, Abreu et al. 2002, 2003, Hausmann et al.
2002, Lorenz et al. 2002, Backhed \& Hornef 2003, Fan \& Malik 2003). Discovery of a naturally occurring mutation in mice for the TLR4 gene (Takeda et al. 2003) was central to our understanding of the importance of TLRs. In particular, these mice were observed to be hyporesponsive to LPS (Backhed \& Hornef 2003, Sabroe et al. 2003). In humans, a number of alleles of TLR4 have been identified and are associated with an increased risk of septic shock (Fenton \& Golenbock 1998, Abreu et al. 2002, 2003, Hausmann et al. 2002, Lorenz et al. 2002, Backhed \& Hornef 2003, Fan \& Malik 2003, Sabroe et al. 2003). Although TLR4 has been shown to interact with heat shock proteins and taxol, arguably the most important role for TLR4 is as a cellular receptor for bacterial LPS, a central bacterial cell wall component comprising $\sim 13 \%$ of the gram negative envelope (Fenton \& Golenbock 1998, Cario et al. 2000, Viriyakosol et al. 2000, Abreu et al. 2002, 2003, Hausmann et al. 2002, Lorenz et al. 2002, Backhed \& Hornef 2003, Fan \& Malik 2003).

It is well known that LPS elicits a robust inflammatory response from the mammalian immune system producing a variety of effects. LPS-induced signaling occurs after a series of binding interactions, first with LPS binding protein followed by transfer of LPS to CD14, which is a GPIlinked receptor that may be present on the cell surface or exist as a soluble form in the serum (Fenton \& Golenbock 1998, Viriyakosol et al. 2000). LPS bound to CD14 is then presented to TLR4, which then initiates a signaling cascade through MD-2, a surface expressed protein that associates with the extracellular domain of TLR4 and LPS. In this light, it is important to note that TLR4 and other TLRs in general, function as a signal transducer and does not appear to actually bind directly to LPS (Sabroe et al. 2003). Upon activation of TLR4, the adaptor protein MyD88 is recruited to the intracellular surface to activate a host of molecules in the TLR activation cascade ultimately leading to cytokine production, recruitment of immune cells, and destruction of pathogenic organisms (Sabroe et al. 2003, Takeda et al. 2003). MyD88 independent signaling pathways have also been described for TLR functions in dendritic cells (Takeda et al. 2003), which goes beyond the scope of this review.

As opposed to TLR4, TLR2 has been shown to mediate responses against a variety of other bacterial components such as peptidoglycans, lipoteichoic acids, mannuronic acids, zymosan and bacterial lipoproteins (Sabroe et al. 2003, Takeda et al. 2003). The binding of TLR2 to these ligands is complicated in that bacterial lipoproteins containing tri-acetylated cysteines signal through a heterodimeric complex of TLR2 and TLR6, whereas bacterial lipoproteins containing di-acetylated cysteines signal through a heterodimeric complex of TLR2 with TLR1 (Sabroe et al. 2003, Takeda et al. 2003). Other TLRs signal in response to double-stranded RNA from viruses (TLR3), flagellin (component of flagellated gram negative bacteria) (TLR5), imidazoquinoline and viral compounds (TLR7), and bacterial DNA CpG motifs (TLR9) (Sabroe et al. 2003, Takeda et al. 2003). Currently, the ligands for TLR8 and TLR10 are unknown (Takeda et al. 2003) Recently, an eleventh TLR has been characterized and has been shown to specifically recognize and protect 
against uropathogenic bacteria (Zhang et al. 2004). As research in this area progresses, it is anticipated that new TLR ligands as well as additional TLRs will be discovered in the future.

\section{Epithelial responses to microbes as a key regulator of PMN transepithelial migration}

During normal physiological conditions, the intestinal epithelium is not inflamed which is due in large part to epithelial tight junctions that restrict the passage of LPS or bacteria from the lumen (Nusrat et al. 2000). Consequently, the epithelial barrier restricts exposure of TLRs on the basolateral epithelial membrane and on underlying immune cells to pro-inflammatory microbial-derived ligands. Given the important role of the epithelial tight junction, it is easy to envision how disruption of the epithelial barrier or how translocation of bacterial products across the epithelium could result in activation of TLRs. Indeed, despite the presence of $10^{14}$ bacteria per gram of tissue in the colon (Abreu et al. 2003) that produce high levels of immunoreactive LPS (Lorenz et al. 2002), the mucosal immune system remains remarkably at a basal physiological state. The fact that epithelial tissues do not express apical GPI-linked CD14 may explain the absence of an inflammatory response to the normal flora (Fenton \& Golenbock 1998, Viriyakosol et al. 2000). In addition, epithelial cells were originally reported to lack expression of TLR4, which also explains why inflammatory responses to bacteria and their products are reduced (Hecht 1999, Cario \& Podolsky 2000, Cario et al. 2000). However, recent studies have demonstrated that TLR4 and MD-2 are expressed by a number of epithelial cells, but at low levels (Abreu et al. 2002, 2003, Backhed \& Hornef 2003). Furthermore, co-transfection of intestinal epithelial cells with TLR4 and MD-2 enhanced LPS responsiveness, thus suggesting that low expression levels of TLR4 and MD-2 may explain epithelial hyporesponsiveness to lumenal LPS (Abreu et al. 2002, 2003). However, it has been reported that TLR2 and TLR4 expression is up-regulated under inflammatory conditions (Abreu et al. 2002, 2003, Hausmann et al. 2002), which could provide a mechanism for certain inflammatory diseases of the intestine. Indeed, there is a report of increased TLR4 expression in the intestinal epithelium of patients with inflammatory bowel disease (Cario \& Podolsky 2000). Whether TLR4 expression is a cause or an effect of disease is unclear, but it does underscore the importance of the gastrointestinal epithelium in preventing excessive and uncontrolled inflammation.

Despite the above observations, epithelial cells located at the base of the small intestinal crypts called Paneth cells secrete antibacterial peptides called defensins in response to LPS or bacterial lipoprotein (Takeda et al. 2003). In vitro studies with human epithelial cells and bacterial lipoprotein led to the observation that TLR2 can act to mediate induction of $\beta$-defensin-2 (Takeda et al. 2003). Since the small intestinal crypt microenvironment where Paneth cells reside is relatively sterile, it is likely that TLRmediated responses to microbial products help to maintain this sterile environment through secretion of these anti-microbial peptides. Conversely, the relative sterility of the small intestine may allow for the expression of TLR4 in the small intestinal epithelium without pro-inflammatory consequences (Backhed \& Hornef 2003). Currently, the role of TLR4 signaling in the epithelial cell remains poorly understood and further studies need to determine the differences between the small intestinal and the colonic epithelium.

The localization of TLRs on epithelial cells is variable and cell specific (Gewirtz et al. 2001, Hornef et al. 2002, Backhed \& Hornef 2003, Ortega-Cava et al. 2003). While TLR2 and TLR4 have been shown to reside on the cell surface of macrophages(Ortega-Cava et al. 2003), in intestinal epithelial cells TLR4 has been shown to localize to the Golgi apparatus (Hornef et al. 2002, Backhed \& Hornef 2003), indicating that responsiveness of the epithelium may involve some sort of cellular processing. While some controversy exists, it is generally accepted that TLR5, the receptor for the gram negative bacterial product flagellin, is restricted to the basolateral side of the intestinal epithelium (Gewirtz et al. 2001). Activation of TLR5 by flagellin has been elegantly linked to activation of a pro-inflammatory cascade resulting in basolaterally polarized secretion of the PMN chemoattractant IL-8 (Reed et al. 2002). Studies on pathogenic and non-pathogenic microorganisms have revealed the ability of intact flagellated bacteria, such as Salmonella typhimurium, to facilitate translocation of flagellin across epithelial monolayers (Hershberg 2002). Alternatively, altered mucosal permeability as has been described in chronic inflammatory bowel disease, could result in basolaterally expressed TLR5 being activated by flagellin delivered through a leaky paracellular space. The end result in both scenarios is stimulation of epithelial cells to release pro-inflammatory molecules such as IL-8 that, in turn, serve to drive mucosal inflammation as detailed in the above sections. Despite this important function of TLR5, we are just beginning to understand how epithelial TLRs regulate mucosal inflammation.

\section{TLR-mediated responses of PMNs}

PMNs represent a central component of the innate immune response (Liu et al. 2004), acting as primary responders by rapidly migrating into inflamed tissues and subsequently employing potent effector mechanisms such as phagocytosis, production of reactive oxygen species, and the release of inflammatory mediators and antimicrobial substances (Ben-Baruch et al. 1995, Greenberg $\&$ Grinstein 2002). PMNs detect the presence of bacteria and bacterial products by expressing TLR on their surface, enabling for an effective antimicrobial response (Hayashi et al. 2003). Although it has been shown that PMN express all TLRs except TLR3 (Hayashi et al. 2003), very few studies have yet to detail the role of TLRs in these cells. In contrast, most studies of TLRs in leukocytes have involved macrophages. Hayashi et al. (2003) reported that exposure of PMNs to TLR agonists resulted in production of IL-8 and shedding of L-selectin from the cell surface. In addition, there was upregulation of CD11b/ CD18 to the cell surface, production of superoxide, and an increase in the rate of phagocytosis (Hayashi et al. 2003). Others have reported increased PMN chemotaxis 
in the presence of a TLR4 agonist (Fan \& Malik 2003). It is clear that TLR agonists appear to have multiple effects on PMNs (Fan \& Malik 2003, Hayashi et al. 2003). Unpublished observations from our group have revealed that residual bacterial lipoprotein in LPS preparations has more potent inhibitory effects on PMN chemotaxis than highly purified LPS. These observations suggest that TLR2 likely plays an important role in regulating PMN chemotactic responses to bacteria. In agreement with this observation, Hayashi et al. (2003), have also reported reduced chemotaxis to IL-8 in TLR-agonist stimulated PMN. The physiological relevance of such is not yet known but it is easy to envision inhibited migration serving as a "stop signal" for migrating PMN once they have reached the stimulus. Indeed, inhibition of PMN chemotaxis to the site of infection by diffusion of bacterial products or by initial bacterial invasion into deeper underlying tissues could possibly facilitate the progression of microbial colonization at distal sites of infection. Clearly this is a fascinating area that warrants further investigation

\section{Conclusion}

In this review, we have briefly covered some aspects of mucosal immunity involving the TLRs, the intestinal epithelium, and PMN transmigration. The innate immune system detects the invasion of microorganisms through TLRs that recognize microbial components and triggers inflammatory responses. A major feature of inflammatory diseases involving mucosal surfaces appears to be dysregulation of the innate immune response. Since PMN transepithelial migration is such an important component of innate immunity, understanding molecular determinants of this cellular response and the role of TLRs in its regulation will be a critical avenue of future research.

\section{REFERENCES}

Abreu MT, Arnold ET, Thomas LS, Gonsky R, Zhou Y, Hu B, Arditi M 2002. TLR4 and MD-2 expression is regulated by immune-mediated signals in human intestinal epithelial cells. J Biol Chem 277: 20431-20437.

Abreu MT, Thomas LS, Arnold ET, Lukasek K, Michelsen KS, Arditi M 2003. TLR signaling at the intestinal epithelial interface. J Endotoxin Res 9: 322-330.

Agace WW, Patarroyo M, Svensson M, Carlemalm E, Svanborg C 1995. Escherichia coli induces transuroepithelial neutrophil migration by an intercellular adhesion molecule-1-dependent mechanism. Infect Immun 63: 4054-4062.

Arrate MP, Rodriguez JM, Tran TM, Brock TA, Cunningham SA 2001. Cloning of human junctional adhesion molecule 3 (JAM3) and its identification as the JAM2 counter-receptor. J Biol Chem 276: 45826-45832.

Aurrand-Lions M, Duncan L, Ballestrem C, Imhof BA 2001a. JAM-2, a novel immunoglobulin superfamily molecule, expressed by endothelial and lymphatic cells. J Biol Chem 276: 2733-2741.

Aurrand-Lions M, Johnson-Leger C, Wong C, Du Pasquier L, Imhof BA 2001b. Heterogeneity of endothelial junctions is reflected by differential expression and specific subcellular localization of the three JAM family members. Blood 98: 3699-3707.
Backhed F, Hornef M 2003. Toll-like receptor 4-mediated signaling by epithelial surfaces: necessity or threat? Microbes Infect 5: 951-959.

Balsam LB, Liang TW, Parkos CA 1998. Functional mapping of CD11b/CD18 epitopes important in neutrophil-epithelial interactions: a central role of the I domain. J Immunol 160: 5058-5065.

Barton ES, Forrest JC, Connolly JL, Chappell JD, Liu Y, Schnell FJ, Nusrat A, Parkos CA, Dermody TS 2001. Junction adhesion molecule is a receptor for reovirus. Cell 104: 441451.

Ben-Baruch A, Michiel DF, Oppenheim JJ 1995. Signals and receptors involved in recruitment of inflammatory cells. $J$ Biol Chem 270: 11703-11706.

Bergelson JM, Cunningham JA, Droguett G, Kurt-Jones EA, Krithiras A, Hong JS, Horowitz MS, Crowell RI, Finberg RW 1997. Isolation of a common receptor for coxsackie B viruses and adenoviruses 2 and 5. Science 283: 2080-2082.

Brown E 2001. Integrin-associated protein (CD47): an unusual activator of $\mathrm{G}$ protein signaling. J Clin Invest 107: 14991500 .

Cario E, Podolsky DK 2000. Differential alteration in intestinal epithelial cell expression of toll-like receptor 3 (TLR3) and TLR4 in inflammatory bowel disease. Infect Immun 68: 7010-7017.

Cario E, Rosenberg IM, Brandwein LP, Beck L, Reinecker HC, Podolsky DK 2000. Lipopolysaccharide activates distinct signaling pathways in intestinal epithelial cell lines expressing Toll-like receptors. J Immunol 164: 966-972.

Cohen CJ, Shieh JT, Pickles RJ, Okegawa T, Hsieh JT, Bergelson JM 2001. The coxsackievirus and adenovirus receptor is a transmembrane component of the tight junction. Proc Natl Acad Sci USA 98: 15191-15196.

Colgan SP, Parkos CA, McGuirk D, Brady HR, Papayianni AA, Frendl G, Madara JL 1995. Receptors involved in carbohydrate binding modulate intestinal epithelial-neutrophil interactions. J Biol Chem 270: 10531-10539.

Cunningham SA, Arrate MP, Rodriguez JM, Bjercke RJ, Vanderslice P, Morris AP, Brock TA 2000. A novel protein with homology to the junctional adhesion molecule. Characterization of leukocyte interactions. J Biol Chem 275: 34750-34756.

Diamond MS, Alon R, Parkos CA, Quinn MT, Springer TA 1995. Heparin is an adhesive ligand for the leukocyte integrin Mac-1 (CD11b/CD1). J Cell Biol 130: 1473-1482.

Diamond MS, Staunton DE, de Fougerolles AR, Stacker SA, Garcia-Aguilar J, Hibbs ML, Springer TA 1990. ICAM-1 (CD54): a counter-receptor for Mac-1 (CD11b/CD18). $J$ Cell Biol 111: 3129-3139.

Ebnet K, Schulz CU, Meyer Zu Brickwedde MK, Pendl GG, Vestweber D 2000. Junctional adhesion molecule interacts with the PDZ domain-containing proteins AF-6 and ZO-1. J Biol Chem 275: 27979-27988.

Ebnet K, Suzuki A, Horikoshi Y, Hirose T, Meyer Zu Brickwedde MK, Ohno S, Vestweber D 2001. The cell polarity protein ASIP/PAR-3 directly associates with junctional adhesion molecule (JAM). Embo J 20: 3738-3748.

Edens HA, Levi BP, Jaye DL, Walsh S, Reaves TA, Turner JR, 
Nusrat A, Parkos CA 2002. Neutrophil transepithelial migration: evidence for sequential, contact- dependent signaling events and enhanced paracellular permeability independent of transjunctional migration. J Immunol 169: 476-486.

Fan J, Malik AB 2003. Toll-like receptor-4 (TLR4) signaling augments chemokine-induced neutrophil migration by modulating cell surface expression of chemokine receptors. Nat Med 9: 315-321.

Fenton MJ, Golenbock DT 1998. LPS-binding proteins and receptors. J Leukoc Biol 64: 25-32.

Gewirtz AT, Navas TA, Lyons S, Godowski PJ, Madara JL 2001. Cutting edge: bacterial flagellin activates basolaterally expressed TLR5 to induce epithelial proinflammatory gene expression. J Immunol 167: 1882-1885.

Greenberg S, Grinstein S 2002. Phagocytosis and innate immunity. Curr Opin Immunol 14: 136-145.

Hamazaki Y, Itoh M, Sasaki H, Furuse M, Tsukita S 2002. Multi-PDZ domain protein 1 (MUPP1) is concentrated at tight junctions through its possible interaction with claudin1 and junctional adhesion molecule. J Biol Chem 277: 455461.

Hausmann M, Kiessling S, Mestermann S, Webb G, Spottl T, Andus T, Scholmerich J, Herfarth H, Ray K, Falk W, Rogler G 2002. Toll-like receptors 2 and 4 are up-regulated during intestinal inflammation. Gastroenterology 122: 1987-2000.

Hawker PC, McKay JS, Turnberg LA 1980. Electrolyte transport across colonic mucosa from patients with inflammatory bowel disease. Gastroenterology 79: 508-511.

Hayashi F, Means TK, Luster AD 2003. Toll-like receptors stimulate human neutrophil function. Blood 102: 2660-2669.

Hecht G 1999. Innate mechanisms of epithelial host defense: spotlight on intestine. Am J Physiol 277: C351-358.

Hershberg RM 2002. The epithelial cell cytoskeleton and intracellular trafficking. V. Polarized compartmentalization of antigen processing and Toll-like receptor signaling in intestinal epithelial cells. Am J Physiol Gastrointest Liver Physiol 283: G833-839.

Hirabayashi S, Tajima M, Yao I, Nishimura W, Mori H, Hata Y 2003. JAM4, a Junctional Cell Adhesion Molecule Interacting with a Tight Junction Protein, MAGI-1. Mol Cell Biol 23: 4267-4282.

Hornef MW, Frisan T, Vandewalle A, Normark S, RichterDahlfors A 2002. Toll-like receptor 4 resides in the Golgi apparatus and colocalizes with internalized lipopolysaccharide in intestinal epithelial cells. J Exp Med 195: 559570 .

Jiang P, Lagenaur CF, Narayanan V 1999. Integrin-associated protein is a ligand for the P84 neural adhesion molecule. $J$ Biol Chem 274: 559-562.

Kopp E, Medzhitov R 2003. Recognition of microbial infection by Toll-like receptors. Curr Opin Immunol 15: 396401.

Koyama S, Rennard SI, Leikauf GD, Shoji S, von Essen S, Claasen L, Robbins RA 1991. Endotoxin stimulates bronchial epithelial cells to release chemotactic factors for neutrophils: a potential mechanism for neutrophil recruitment, cytotoxicity, and inhibition of proliferation in bronchial inflammation. J Immunol 147: 4293-4301.
Liang TW, Chiu HH, Gurney A, Sidle A, Tumas DB, Schow P, Foster J, Klassen T, Dennis K, DeMarco RA, Pham T, Frantz G, Fong S. 2002. Vascular endothelial-junctional adhesion molecule (VE-JAM)/JAM 2 interacts with T, NK, and dendritic cells through JAM 3. J Immunol 168: 16181626.

Lindberg FP, Bullard DC, Caver TE, Gresham HD, Beaudet AL, Brown EJ 1996. Decreased resistance to bacterial infection and granulocyte defects in iap-deficient mice. Science 274: 795-798.

Lindberg FP, Gresham HD, Schwarz E, Brown EJ 1993. Molecular cloning of integrin-associated protein: an immunoglobulin family member with multiple membrane-spanning domains implicated in alpha $\mathrm{v}$ beta 3 -dependent ligand binding. J Cell Biol 123: 485-496.

Liu Y, Buhring HJ, Zen K, Burst SL, Schnell FJ, Williams IR, Parkos CA 2002. Signal regulatory protein (SIRPalpha), a cellular ligand for CD47, regulates neutrophil transmigration. J Biol Chem 277: 10028-10036.

Liu Y, Merlin D, Burst SL, Pochet M, Madara JL, Parkos CA 2001. The role of CD47 in neutrophil transmigration. Increased rate of migration correlates with increased cell surface expression of CD47. J Biol Chem 276: 40156-40166.

Liu Y, Nusrat A, Schnell FJ, Reaves TA, Walsh S, Pochet M, Parkos CA 2000. Human junction adhesion molecule regulates tight junction resealing in epithelia. J Cell Sci 113: 2363-2374.

Liu Y, Shaw SK, Ma S, Yang L, Luscinskas FW, Parkos CA 2004. Regulation of leukocyte transmigration: cell surface interactions and signaling events. J Immunol 172: 7-13.

Lorenz E, Patel DD, Hartung T, Schwartz DA 2002. Toll-like receptor 4 (TLR4)-deficient murine macrophage cell line as an in vitro assay system to show TLR4-independent signaling of Bacteroides fragilis lipopolysaccharide. Infect Immun 70: 4892-4896.

Madara JL, Patapoff TW, Gillece-Castro B, Colgan SP, Parkos CA, Delp C, Mrsny RJ 1993. 5'-AMP is the neutrophilderived paracrine factor that ilicits chloride secretion from T84 epithelial monolayers. J Clin Invest 91: 2320-2325.

Malergue F, Galland F, Martin F, Mansuelle P, Aurrand-Lions M, Naquet P 1998. A novel immunoglobulin superfamily junctional molecule expressed by antigen presenting cells, endothelial cells and platelets. Mol Immunol 35: 1111-1119.

Martinez-Estrada OM, Villa A, Breviario F, Orsenigo F, Dejana E, Bazzoni G 2001. Association of junctional adhesion molecule with calcium/calmodulin-dependent serine protein kinase (CASK/LIN-2) in human epithelial caco-2 cells. $J$ Biol Chem 276: 9291-9296.

Martin-Padura I, Lostaglio S, Schneemann M, Williams L, Romano M, Fruscella P, Panzeri C, Stoppacciaro A, Ruco L, Villa A, Simmons D, Dejana E 1998. Junctional adhesion molecule, a novel member of the immunoglobulin superfamily that distributes at intercellular junctions and modulates monocyte transmigration. J Cell Biol 142: 117-127.

Medzhitov R, Janeway Jr CA 1997. Innate immunity: impact on the adaptive immune response. Curr Opin Immunol 9: 4-9.

Medzhitov R, Preston-Hurlburt P, Janeway Jr CA 1997. A human homologue of the Drosophila Toll protein signals 
activation of adaptive immunity. Nature 388: 394-397.

Milks LC, Brontoli MJ, Cramer EB 1983. Epithelial permeability and the transepithelial migration of human neutrophils. J Cell Biol 96: 1241-1247.

Moog-Lutz C, Cave-Riant F, Guibal FC, Breau MA, Di Gioia Y, Couraud PO, Cayre YE, Bourdoulous S, Lutz PG 2003. JAML, a novel protein with characteristics of a junctional adhesion molecule, is induced during differentiation of myeloid leukemia cells. Blood 102: 3371-3378.

Naik UP, Naik MU, Eckfeld K, Martin-DeLeon P, Spychala J 2001. Characterization and chromosomal localization of JAM-1, a platelet receptor for a stimulatory monoclonal antibody. J Cell Sci 114: 539-547.

Nash S, Stafford J, Madara JL 1987. Effects of polymorphonuclear leukocyte transmigration on barrier function of cultured intestinal epithelial monolayers. J Clin Invest 80: 11041113.

Nusrat A, Parkos CA, Liang TW, Carnes DK, Madara JL 1997. Neutrophil migration across model intestinal epithelia: monolayer disruption and subsequent events in epithelial repair. Gastroenterology 113: 1489-1500.

Nusrat A, Turner JR, Madara JL 2000. Molecular physiology and pathophysiology of tight junctions. IV. Regulation of tight junctions by extracellular stimuli: nutrients, cytokines, and immune cells. Am J Physiol Gastrointest Liver Physiol 279: G851-857.

Ortega-Cava CF, Ishihara S, Rumi MA, Kawashima K, Ishimura N, Kazumori H, Udagawa J, Kadowaki Y, Kinoshita Y 2003. Strategic compartmentalization of Toll-like receptor 4 in the mouse gut. J Immunol 170: 3977-3985.

Ozaki H, Ishii K, Horiuchi H, Arai H, Kawamoto T, Okawa K, Iwamatsu A, Kita T 1999. Cutting edge: combined treatment of TNF-alpha and IFN-gamma causes redistribution of junctional adhesion molecule in human endothelial cells. J Immunol 163: 553-557.

Palmeri D, van Zante A, Huang CC, Hemmerich S, Rosen SD 2000. Vascular endothelial junction-associated molecule, a novel member of the immunoglobulin superfamily, is localized to intercellular boundaries of endothelial cells. J Biol Chem 275: 19139-19145.

Parkos CA 1997. Cell adhesion and migration. I. Neutrophil adhesive interactions with intestinal epithelium. Am J Physiol 273: G763-768.

Parkos CA, Colgan SP, Liang TW, Nusrat A, Bacarra AE, Carnes DK, Madara JL 1996. CD47 mediates post-adhesive events required for neutrophil migration across polarized intestinal epithelia. J Cell Biol 132: 437-450.

Parkos CA, Delp C, Arnaout MA, Madara JL 1991. Neutrophil migration across a cultured intestinal epithelium. Dependence on a CD11b/CD18-mediated event and enhanced efficiency in physiological direction. J Clin Invest 88: 16051612.

Parsons PE, Sugahara K, Cott GR, Mason RJ, Henson PM 1987. The effect of neutrophil migration and prolonged neutrophil contact on epithelial permeability. Am J Pathol 129: 302-312.

Prossnitz ER, Ye RD 1997. The N-formyl peptide receptor: a model for the study of chemoattractant receptor structure and function. Pharmacol Ther 74: 73-102.
Ramos CD, Heluy-Neto NE, Ribeiro RA, Ferreira SH, Cunha FQ 2003. Neutrophil migration induced by IL-8-activated mast cells is mediated by CINC-1. Cytokine 21: 214-223.

Reed KA, Hobert ME, Kolenda CE, Sands KA, Rathman M, O'Connor M, Lyons S, Gewirtz AT, Sansonetti PJ, Madara JL 2002. The Salmonella typhimurium flagellar basal body protein FliE is required for flagellin production and to induce a proinflammatory response in epithelial cells. J Biol Chem 277: 13346-13353.

Sabroe I, Read RC, Whyte MK, Dockrell DH, Vogel SN, Dower SK 2003. Toll-like receptors in health and disease: complex questions remain. J Immunol 171: 1630-1635.

Santoso S, Sachs UJ, Kroll H, Linder M, Ruf A, Preissner KT, Chavakis T 2002. The junctional adhesion molecule 3 (JAM3 ) on human platelets is a counterreceptor for the leukocyte integrin Mac-1. J Exp Med 196: 679-691.

Sobocka MB, Sobocki T, Banerjee P, Weiss C, Rushbrook JI, Norin AJ, Hartwig J, Salifu MO, Markell MS, Babinska A, Ehrlich YH, Kornecki E 2000. Cloning of the human platelet F11 receptor: a cell adhesion molecule member of the immunoglobulin superfamily involved in platelet aggregation. Blood 95: 2600-2609.

Stofega MR, Argetsinger LS, Wang H, Ullrich A, Carter-Su C 2000. Negative regulation of growth hormone receptor/JAK2 signaling by signal regulatory protein alpha. $J$ Biol Chem 275: 28222-28229.

Strohmeier GR, Lencer WI, Patapoff TW, Thompson LF, Carlson SL, Moe SJ, Carnes D, Mrsny RJ, Madara JL 1997. Surface expression, polarization and functional significance of CD73 in human intestinal epithelia. J Clin Invest 99: 2588-2601.

Strohmeier GR, Reppert SM, Lencer WI, Madara JL 1995. The A2b adenosine receptor mediates cAMP responses to adenosine receptor agonists in human intestinal epithelia. $J$ Biol Chem 270: 2387-2394.

Takeda K, Kaisho T, Akira S 2003. Toll-like receptors. Annu Rev Immunol 21: 335-376.

Tavares-Murta BM, Zaparoli M, Ferreira RB, Silva-Vergara ML, Oliveira CH, Murta EF, Ferreira SH, Cunha FQ 2002. Failure of neutrophil chemotactic function in septic patients. Crit Care Med 30: 1056-1061.

Tosi MF, Stark JM, Smith CW, Hamedani A, Gruenert DC, Infeld MD 1992. Induction of ICAM-1 expression on human airway epithelial cells by inflammatory cytokines: effects on neutrophil-epithelial cell adhesion. Am J Resp Cell Mol Biol 7: 214-221.

Viriyakosol S, Mathison JC, Tobias PS, Kirkland TN 2000. Structure-function analysis of CD14 as a soluble receptor for lipopolysaccharide. J Biol Chem 275: 3144-3149.

Weiland JE, Davis WB, Holter JF, Mohammed JR, Dorinsky PM, Gadek JE. 1986. Lung neutrophils in the adult respiratory distress syndrome. Clinical and pathophysiologic significance. Am Rev Respir Dis 133: 218-225.

Williams LA, Martin-Padura I, Dejana E, Hogg N, Simmons DL 1999. Identification and characterisation of human Junctional Adhesion Molecule (JAM). Mol Immunol 36: 11751188.

Zen K, Babbin BA, Liu Y, Whelan JB, Nusrat A, Parkos CA 2004. JAM-C is a component of desmosomes and a ligand 
for CD11b/CD18 - mediated neutrophil transepithelial migration. Mol Biol Cell 15: 3926-3937.

Zen K, Parkos CA 2003. Leukocyte-epithelial interactions. Curr Opin Cell Biol 15: 557-564.

Zen K, Liu Y, Cairo D, Parkos CA 2002. CD11b/CD18-dependent interactions of neutrophils with intestinal epithelium are mediated by fucosylated proteoglycans. J Immunol 169: 5270-5278.

Zhang D, Zhang G, Hayden MS, Greenblatt MB, Bussey C, Flavell RA, Ghosh S 2004. A toll-like receptor that prevents infection by uropathogenic bacteria. Science 303: 1522-1526. 